\title{
'HIGHER REALITY', HIGHER LEARNING? CHALLENGING TRAINEE SCIENCE TEACHER'S CONCEPTIONS OF THE NATURE OF THE WORLD AND THE NATURE OF SCIENCE
}

\author{
A. Weller \\ University of East London (UNITED KINGDOM)
}

\begin{abstract}
The focus of this small-scale qualitative study is to explore an alternative way of gaining knowledge about the 'world' and the impact this has on pre-service secondary science trainees in England.

Studies exist on the relationship between science and religion for example Ratanakul (2002) [1] and Thurow (2013) [2]. However, the relationship between science and religion is an under researched topic within Teacher Education.

This study will examine the interplay between Buddhism and science with a particular emphasis on the Abhidhamma. Abhidhamma translates as 'higher reality' or 'higher teaching' from the Theravada tradition of Buddhism [3] It is the author's opinion that this part of the scriptures has not been accessible to the English speaking community until recently. English translations of this part of the original text and English commentaries are now only just being made available to the public. Science trainees will not have been exposed to this before.
\end{abstract}

This exploratory survey was in the context of the diverse urban background setting of East London. A 1.5 hour session was held at the university comprising 11 pre-service secondary science trainees. The session explored the idea that science has a concept of reality as its object of understanding and that Buddhism has a reality as its object of understanding. The underlying pedagogy behind the session was to use concepts in the right way to understand reality. A questionnaire at the end of the session showed that $100 \%$ of trainees found the session useful. $40 \%$ of trainees agreed that the understanding science has of reality is zero.

The study will contribute to the debate about the role and relevance of religion to 21 st century science. It will help clarify the relationship between Buddhism and science particularly as taught to the 11-16 year age range in some secondary schools. It introduces students to new meanings of the word 'spiritually' and overcomes some common misconceptions about Buddhism.

Keywords: scientism, science and religion, buddhism, abhidhamma, mindfulness, morality

\section{INTRODUCTION}

In London, we teach in one of the most diverse religious and ethnic populations in Europe. We need to teach with empathy and understand the faith issues and conflicts, which surround the teaching of science without compromising on the science itself. We also need to understand the boundaries of science and not make assumptions, which go beyond what we know.

According to the 2011 Census, the largest religious groupings in London are Christians (48.4 per cent), followed by those of no religion (20.7 per cent), no response (8.5 per cent), Muslims (12.4 per cent), Hindus (5.0 per cent), Jews (1.8 per cent), Sikhs (1.5 per cent), Buddhists (1.0 per cent) and other (0.6 per cent). (Cited in) [4]

Although Buddhism only represents $1 \%$ of the faiths in London, it is taught in many schools throughout the UK as a part of a broad religious curriculum. Therefore, there are benefits to understanding its relationship with science and being able to answer possible conflicting views.

This cross-curricular approach also has benefits in being able to borrow teaching pedagogy from Religious Education. This extract is from The National Curriculum guidance for RE: 
"...encourages pupils to learn from different religions, beliefs, values and traditions while exploring their own beliefs and questions of meaning. It challenges pupils to reflect on, consider, analyse interpret and evaluate issues of truth, belief, faith and ethics and to communicate their responses." [5]

This forms the basis of the paper and session; we use 'higher reality' to challenge.

\subsection{The Card Exchange}

The Card Exchange [6] is a typical activity for science teacher trainees to clarify their views on the nature of science. Science trainees, in small groups of three or four, discuss and arrange a series of statements on science in order, according to their closest match to the way science works. The below statements sit very uncomfortably in the mix.

"Science and Religion are fundamentally at odds with one another." [6]

"Only science can tell us what is really true about the world." [6]

The idea of the session stems from this activity. We use religion, in this case, the Abhidhamma to challenge trainees with not only the nature science but also the nature of reality itself.

All the understanding we have, no matter whether it is science, mathematics, philosophy, language is intellectual understanding. However, is there another type of understanding? Is there another way, which can tell us what is really true about the world? If so how does it work? Is it higher? This paper explores a different way of understanding, its cause, its object and its results, through the 'vehicle' of the science lesson.

\section{MISCONCEPTIONS, PRECONCEPTIONS AND ASSUMPTIONS}

\subsection{The light cycle}

If you ask science trainees teachers this question: "Can you cycle faster than the speed of light?" The answer is invariably no. The next question. Why is this wrong? Is often confronted by complete silence.

This is an open question disguised as a closed question. There is no mention of the speed of light, which we, which we reasonably assume to be seriously, fast. It is, but only in a vacuum. The speed of light can be slowed down to 17 metres per second in some substances and you can cycle faster than that! [7].

Why is it so difficult to consider the following question? Why is this wrong? Is it the embedded assumption we have about the nature of light i.e. seriously fast or is it that we have to think laterally against convention? We all have 'reasonable' assumptions about the nature of the world, religion and the nature of reality.

\subsection{Common assumptions}

One 'reasonable' assumption is that we know more about the world now than we did 2500 years ago. Another is that 2500 years ago the views on the way the world worked were medieval and primitive.

Many have the idea that Buddhism is a religion dependent on faith and worship. James Holt, Senior lecturer in Religious Education, has this to say about the categorisation of Buddhism.

"In beginning any discussion of Buddhism it is important to ask the question: 'Is Buddhism a religion?' This question can be asked because it challenges traditional assumptions about the characteristic of religion. Buddhism is generally an atheistic religion; a religion without God. As such some would categorise Buddhism as not being a religion." [5]

Another 'reasonable' assumption, which some scientists assert, is that science is the only way of understanding the world or that religion cannot understand the world.

Richard Dawkin speaking on BBC's Heart of the matter:

"What worries me about religion is that it teaches people to be satisfied with not understanding." [8]

However, he does not appear to consider Buddhism as a religion, writing in his book The God Delusion (p37): 
"And I shall not be concerned at all with other religions such as Buddhism or Confucianism. Indeed, there is something to be said for treating these not as religions at all but as ethical systems or philosophies of life." [9]

Do we also make subtle but 'reasonable' assumptions about the nature of reality itself? Assumptions, which are unknown and can, cause us all manner of problems.

Our many misconceptions, preconceptions and assumptions can prevent us from considering another way of understanding the world.

In the Tipitaka, The counfounding of Saddhamma, it is written that the Buddhists destroy Buddhism by not considering it carefully enough. [10] (Gradual Sayings, paragraph iv, 154). It can be seen that there are many different practices including: fishing, chanting, swimming in the Ganges, shooting arrows. Many scientists rightly reject what they see as Buddhism but which is in fact a misrepresentation of Buddhism. It would be reasonable to assume that there is now no right understanding of this 2500 year old teaching.

The classroom teacher has a similar problem. James Holt encounters at a parents evening led him to write:

This highlighted for me the concerns that face a teacher of Buddhism as much as a teacher of Hinduism or Christianity; the diversity is so big that we have to acknowledge it while we teach 'classroom Buddhism' [11] (p150).

This is also a problem for researchers. Thupten Jinpa:

Neuroscientists and psychologists are interested in engaging with Buddhist Abhidharma psychology and phenomenology as well as Buddhist contemplative practices to see if research methods and the theoretical framework on the study of the human mind can be enriched through serious engagement with Buddhist thought[12].

Are the researchers researching what is correct or what is fashionable?

\subsection{Overcoming Misconceptions}

In science teacher training, we have similar problems. Graduate trainees have a number of misconceptions, which need to be corrected before they reach the classroom. For example, $90 \%$ of biologists will have the wrong idea that a person in orbit on the International Space Station will have no weight. Around $50 \%$ of physics trainees will have misconceptions over Newton's Third Law. Difficult conceptual problems are often 'dumbed down' into a misconception.

How do we deal with this? We use diagnostic questioning [13], audits and tests. Can science help with Buddhism? Pinit Ratanakul writes:

...a scientific outlook can assist the Buddhist in weeding out the pre-Buddhist magicoanimistic elements that have become entwined with Buddhist teaching and tend to distract the Buddhist from following the Buddhist path to wisdom and compassion [1].

What does the Tipitaka (the teachings of the Buddha) tell us about this problem? Firstly, do not take anything anyone says about the teachings as correct unless it checks out with the Tipitaka. The teachings themselves are the authority (D11, chapter 16) [14]. Secondly check it out with reality (Is there a method? Third fifty, paragraph 152) [15], Thirdly consider it in detail (Gradual Sayings, paragraph iv, 154) [10].

\section{SCIENCE AND BUDDHISM, HARMONY OR CONFLICT?}

Richard Dawkin and Jerry Coyne writing in the Guardian Newspaper. "When two opposite points of view are expressed with equal intensity, the truth does not necessarily lie exactly half way between. It is possible for one side simply to be wrong." [17]

There are two heavyweights at understanding the world: Buddhism and Science. However, they appear to be poles apart. No mention of the laws of physics within Buddhism and no mention of the four Noble Truths in physics.

'Science and Buddhism but which is better? There is only one way to find out? Fight! '[18] 
The above catch line from a comedy TV series could well be asked by a pupil and is one in which I have had to deal with myself at school.

Looking superficially, it would be a 'reasonable' assumption that science is the winner here. Science gives us cures for diseases and all manner of gadgets for easy living and enjoyment. However, what does Buddhism give? What do science and Buddhism have in common? By looking at 14 Big Ideas of Science (Harlen W.) [12], and 14 Big Ideas of Buddhism (compiled by the author) [20]. They only have one Big Idea in common.

All 'worldly' phenomena are conditioned.

Pinit Ratanakul also has this to say:

An obvious analogy is the Buddhist fundamental belief that existence is orderly (itippapccayata) and that humans can discover that order inherent in the structure of physical reality for themselves. This natural order is understood as the law of cause and effect which states the conditionality of all phenomena (paticcasamupapada) [1]

This already clears up some misconceptions of higher authority, faith or belief. It also shows that the science teacher may quite comfortable teaching this subject as he is used to working with this 'Big Idea' in mind.

Thupten Jupta: ...there is a recognition of Buddhism and science as representing investigative traditions in a quest to gain a deeper understanding of reality. [12].

However what is the relationship between them and 'How does Buddhism Work?' How can these two live together without conflict? One possible solution is below:

There are two worlds intertwined. There is another world, a parallel world. There is a different type of understanding, which operates on this parallel world. This world is hidden.

The world we know, is the domain of science, the hidden world is the domain of 'higher reality' the Abhidhamma [3]. The first step in 'higher understanding' is to spot this hidden world, intellectually. This intellectual understanding is not 'higher understanding but the condition for it. The result of developing this understanding is detachment from the idea of self and the eventual eradication of our many faults.

Our many faults, anxieties and grief are rooted in not understanding reality as it is.

\section{THE DEBATE}

The session is a debate with 11 science teacher trainees over a 1.5 -hour period. The session is voluntary; they know the session may be used for an article. There are a wide range of ages, ethnicity and religion within the class. The trainees have already had a discussion on the nature of science using the Card Exchange [6].

The debate centers around the following question with a picture of a round Earth shown on the electronic whiteboard.

The Earth is flat or round. What is the evidence?

Trainees give evidence in the form of; ships masts on the horizon; angle of the sun at different circumferences; pictures from space; circumnavigating the world. Note, the Greeks calculated the radius of the Earth to a good approximation around 200bc. [21]

The question is like our light cycle question (in the Introduction). There is another way of looking at the world, a different 'lens'. As an analogy, the Sun may appear round through an optical telescope but may appear pear shaped through a gamma ray telescope.

As discussed earlier there is a 'hidden' world. We have to find the 'hidden' world.

\subsection{Higher reality, higher pedagogy}

The opposing argument is put using four strategies underpinned by a single pedagogy:

We use concepts in the right way in order to make known realities. (Concepts)[16]

This world of the Earth comes to us through five worlds, five doorways. Seeing, hearing, touching, tasting, smelling. None of these five worlds is round. 
The four strategies are the following:

1. The diagnostic test

2. The Science

3. Lego

4. Shortbread biscuits

\subsubsection{The diagnostic test}

Two simple questions are put to the class.

Firstly, how many objects can you touch?

Only three objects can be touched.

Typical answers such as chair, table, person shows the reality is hidden. We can only touch hardness or softness, hot or cold, motion or pressure.

We experience a reality and this is immediately followed by thinking. Table is a concept the object of thinking.

'We used to think that a cushion or a chair could be experienced through touch. When we are more precise, it is hardness or softness that can be experienced through touch. Because of remembrance of former experiences, we can think of a cushion or chair and we know that they are named "cushion" or "chair". This example can remind us that there is a difference between ultimate realities and concepts we can think of but which are not real in the ultimate sense.' [22](Gorkom, p2)

If we take the word heat, this word represents a reality which can be directly experienced through the body-sense as hot or cold. We do not have to call it by any name. In science, we understand temperature as the average kinetic energy of the molecules. However, this is thinking about the temperature, not the direct experience of temperature.

The second question: What can you see?

The description of what is seen typically computer screen, person, table. However, this does not accurately describe what is seen. There will always be an object that is missed out. Seeing sees what is visible, immediately this is followed by thinking in concepts. This is how TV's are designed. There are no people in the TV!

Person, computer, table, chairs cannot be seen, they are perceived. What is seen is visible object, it is not something. This reality is also hidden in daily life.

\section{Sujin Boriharnwanaket writes in A Survey of Paramatta Dhammas Part V Dialogue on vipassana}

The wording "that which appears through the eyes" describing the characteristic of visible object is altogether appropriate. It explains that visible object is only an element (dhātu) appearing through the eyes so that it can be seen. No matter what colour it is: red, green, blue, yellow or white, a bright or a dull colour, it must appear when it impinges on the rūpa that is eye sense. When someone, after having seen what appears through the eye sense, does not understand realities as they are, there is bound to be attā-saññā. He takes what was seen for people, beings or things. When people are absorbed in different colours, it causes them to think of a "whole", of shape and form, and, thus, there is remembrance (sañña) of the outward appearance of persons and things. When it seems that one sees people, beings or things, there are in reality only different colours that are seen, such as black, white, and the colour of skin, red or yellow.

If people did not interpret different colours or "translate" them into shape and form, they would not conceive them as beings, people or things. Therefore, when we see and we are then absorbed in the shape and form, in the outward appearance (nimitta) and the details of things, we should know that this occurs only because colour appears. When colours appear, we think about them, interpret them and "translate" them into shape and form of different things. [16] 


\subsubsection{Science}

There is a diagram of the eye on the whiteboard at this point. Science backs this up. What can be seen is only what is visible. The rods and cones of the retina are sensitive only to colour, there is no rod and cone sensitive to table. Conventionally, the idea of a thing is an interpretation in the brain.

The same goes for touch. Nerve endings are sensitive only for three objects. There is no sensitivity for a table.

\subsubsection{The Art of Brick}

A picture is now shown from the Art of Brick exhibition [23] showing a picture of a woman's head. With just three colours, we form the idea of a person seen in our minds. The process is the same no matter we are seeing 'real people' or in people in a picture. Person is an idea, conditioned by the visible object which is seen. When we read a book or this computer screen, our mind instantly translates the coloured lines into words. In the same way, the mind translates the different colours of what is seen into something such as a table.

\subsubsection{Shortbread biscuits}

Lastly the below sentences are now on the whiteboard and discussed. The words in capitals represent absolute realities the other words are concepts, the object of thinking. Another type of reality is introduced, a mental reality, a reality which experiences a physical or mental phenomena phenomena. A physical phenomena does not experience anything. For example LIKE is a word which represents a mental phenomenon which can experience taste with liking. TASTE is a physical phenomenon it is an absolute reality, which does not experience anything. SOUND is a reality, guitar is not a reality. SEEING is a reality which experiences visible object. THINKING is a reality but the I or person is not a reality.

I LIKE the TASTE of shortbread biscuits.

I am in a lecture theatre LISTENING to Alan SPEAK.

I LIKE the SOUND of Jimi Hendrix's guitar.

When I TOUCH the gas tap my finger FEELS COLD.

I THINK therefore I am.

The UNDERSTANDING, which understands conditioned REALITIES, is also conditioned

The Abhidhamma, this is an exposition of all realities in detail. The prefix "abhi" is used in the sense of "preponderance" or "distinction". "Abhidhamma" means "higher dhamma" or "dhamma in detail". [3]

'The Abhidhamma uses words to make known realities, but the realities of life are not words.' (Boriharnwanket from memory)

There are only seven physical objects experienced day to day. Visible object, sound, 3 objects touched, smell, taste. No matter you are in Cern, on Mars or in an operating theatre, it is just these seven objects. If anyone were to insist that there are more than seven objects then they are in the realm of belief and speculation. Because of these seven objects the world of concepts is born. Person, iPhone 6, arm, foot, leg. This is life as it is; it is not a theory of life. We live mostly in the 'ocean of concepts'. The realities of life are hidden. In this world of realities there are no people, no tables, no chairs, no computers, no self, just mental and physical phenomena. [3] (Chapter 2). This world of absolute realities is our parallel universe.

Going back to the round Earth. What is seen, no matter the Earth or a football, is not round. What is seen is visible object. Roundness, football are concepts the objects of thinking conditioned by the seeing and remembrance of concepts. The Earth is still round, this is conventional truth. However what is seen is not something, this is a fundamental misconception of reality. This wrong understanding of reality should be got rid of, it will bring unhappiness?

\subsection{Higher learning}

Just as Mendeleev grouped elements according to properties to form the periodic table, all these realities are grouped in different ways in the Abhidhamma for the purpose of understanding them as they are. Abhidamma uses a particular group of concepts to reveal different characteristics of reality. 
All absolute realities have three characteristics. They are impermanent (anicca), not something or self or something (anattā), and unsatisfactory (dukkha).

Going back to our original question. What can you see? If you see people and/or things it indicates there is ignorance of reality. What is seen is visible object. It is just an element, it is not something. It is not self (anatta). However this understanding is not just to be understood at the intellectual level but is to be directly experienced. There is another type of understanding (pañña) which understands the true nature of reality as it is. This understanding will come about when there is studying with awareness of different types of realities. The whole purpose of Buddhism is to understand characteristics of reality as they are. This however is not the thinking about these objects but the direct experience of for example visible object as just a reality, not something. A reality, which can be seen only and cannot be touched.

The right intellectual understanding of the teachings I.e. difference between realities and concepts, the conditionality of phenomena and the true nature of each reality, forms up a condition for the studying of reality with awareness. When realities are studied in this way, understanding can grow to reveal characteristics of reality as they are by direct experience.

By listening and considering, the right conditions are being accumulated for the arising of satipațthāna (mindfulness), awareness and investigation of the characteristics of the realities that are appearing. In this way, realities can be known as they are. Through awareness of realities, one will directly understand the truth in conformity with what one has learnt and understood intellectually, namely, that all dhammas (realities), including satipațhāna and the factors of the eightfold Path, are anattā, non-self. Satipațțāna can arise when there are the right conditions, that is, when mahā-kusala citta (wholesome consciousness) accompanied by paññā has arisen time and again, and paññā has thus been accumulated. Then people will not deviate anymore from the right Path. They will not follow a practice other than being aware of, noticing and considering the nāma (mental) dhammas and the rūpa (physical) dhammas (realities) appearing through the six doors. [16] (Factors of Enlightenment)

\subsection{What are the benefits?}

Understanding characteristics of reality as they are leads to detachment from them. We are very attached to people, but a person cannot be seen or touched only a characteristic of reality can be seen or touched. There will also be detachment from the idea of self. What we take for a self are different realities, which only last a split second. Each reality is conditioned to arise; there is nobody who can exercise control over them. It is higher understanding because the object of understanding is a reality not an idea about reality. 'Reality lies' to us when we have the illusion of permanence and of a self.

Attachment is a condition for aversion. This can be towards ideas as well as sense objects. During the session several daily examples were put up for discussion. For example:

- The cat jumps in front of the television when Strictly Come Dancing (or our favourite programme) is on.

- The Tunbridge Wells resident (upmarket-town) is devastated when Poundland (down-market shop) comes to the City Centre.

- The wife gets agitated when coffee is poured into a tea mug.

- The devastated teenager whose smartphone has run out of battery.

- The unhappy mother who cannot cross the road with her baby due to traffic queuing for a superstore.

If you are a teacher you could try this lovely idea from Teachers TV, authored by Susie Paskins [24] (but watch the video first). With your 11-year-old, pupils get them to colour in a picture of a Mandala for half an hour then get the best-behaved pupil to come forward and explain their picture to the rest of the class. Then tell this person to rip it up and put it in the bin!

\subsection{Summary of the discussion}

There is a difference between an ultimate reality (paramattha dhamma) and a concept e.g. sound and guitar. 
The object of understanding in science is a concept. The object of understanding in mindfulness is a reality. Science is concerned with conventional truth. Mindfulness is the understanding of absolute truth through development of understanding of absolute reality. Science never directly understands a reality, only an idea about reality.

The mechanism for this higher understanding to arise is the intellectual understanding of realities and their conditions. This forms up a condition for the direct studying of realities with awareness. When there is studying with awareness there can be the higher understanding of the characteristic of reality as it is.

Understanding of reality leads to detachment from it.

Attachment is a condition for aversion and all manner of other problems. Immorality is rooted in not understanding reality as it is.

\section{SURVEY RESULTS}

An online survey was conducted after the session. The following questions were put:

Attachment is a condition for aversion?

8 yes, 3 sometimes, 0 no

The session puts forward the idea that science has a concept as its object of understanding; Buddhism has a reality as its object of understanding?

4 true, 6 possibly true, 1 false

The understanding that science has of reality is zero?

4 true, 6 depends on the definition of reality, 1 false

Do you consider the session relevant to your teaching?

11 yes $(100 \%)$

Why do you think it was relevant?

"Because we are going to teach in a very diverse environment with people with very different beliefs."

"It provides me with information just in case students ask about it in class."

"Because it encouraged us to consider other world views, \& other views on reality, which is, ultimately, what most scientists would like to consider science as being about."

"It allowed me to see another perspective that some of my students may hold."

\section{CONCLUSION}

The understanding of the Abhidhamma is a serious challenge to science teacher trainees. It can not only challenge them in the nature of reality itself but also help them clarify their ideas of 'How science works'. It offers them a different perspective on the nature of the world, a glimpse at another way of understanding. Abhidhamma can help move school science forwards. We live in the world of virtual reality headsets, flight simulators. Our scientists need to understand how to trick the mind into this other reality.

A basic understanding of Abhidhamma is the essential key to the development of mindfulness; it opens up the deep meaning of the suttas and can test whether the development of mindfulness is right or wrong.

For example, any practice involving posture. Sitting is merely an idea read out of reality. It matters not that we sit, stand or run. Any practice involving the idea of self-trying; selecting an object, selecting a special time or place, watching or observing. Any practice involving attachment. This path of mindfulness must begin with detachment.

Secular mindfulness is coming into our schools, universities and colleges, largely unchallenged. Yet in these practices there is no evidence that the difference between concept and reality is understood and so we lose the mechanism by which mindfulness arises. The mechanism becomes the idea of self who can cause mindfulness to arise. This is going in the opposite direction to the purpose of 
mindfulness and merely becomes another object of attachment. It is harmful because it misleads us into thinking that it is being developed and it makes it harder to develop correctly.

"Science is a magnificent force, but it is not a teacher of morals. It can perfect machinery, but it adds no moral restraints to protect society from the misuse of the machine. It can also build gigantic intellectual ships, but it constructs no moral rudders for the control of storm-tossed human vessel." Scopes Trial [25]

Science is a 'magnificent force' to understand and benefit this world. However, Science has a domain in which it operates and it is overstretching itself with the domain of this understanding. This "human vessel' is blocking the understanding of the world. It is not interested to develop another way of understanding. It studies only concepts about the world, but never studies reality. We understand temperature as the average kinetic energy of molecules but science does not know how to study the reality of temperature when it appears through the body-sense. If there is no studying of the world, there will not be any knowledge of it.

We should be careful that our belief in science does not prevent us from understanding reality, 'the moral rudder'. The most important thing our pupils and teachers need to learn in science, the $15^{\text {th }}$ 'Big Idea', is that the understanding science has of reality is zero.

\section{ACKNOWLEDGEMENTS}

I would like to thank, The Dhamma Study and Support Foundation, Thailand [26] for answering my many questions and for enabling me to publish their material online and in print [27] [28].

\section{REFERENCES}

[1] P. Ratanakul, 'Buddhism and science: Allies or enemies?', Zygon®, vol. 37, no. 1, pp. 115-120, 2002.

[2] J. C. Thurow, 'Does cognitive science show belief in god to be irrational? The epistemic consequences of the cognitive science of religion', Int. J. Philos. Relig., vol. 74, no. 1, pp. 77-98, Aug. 2013.

[3] N. V. Gorkom, Abhidhamma in Daily Life, Fourth revision edition. London: zolag, 2014.

[4] 'Religion in London', Wikipedia, the free encyclopedia. 14-Apr-2016.

[5] J. Holt, Religious Education in the Secondary School. Routledge, 2014.

[6] V. Kind, Teaching Secondary 'How Science Works', Pap/Cdr St edition. London: Hodder Education, 2008.

[7] 'Lene Hau', 2015. [Online]. Available: http://www.physicscentral.com/explore/people/hau.cfm. [Accessed: 22-May-2015].

[8] 'Heart of the Matter: God under the Microscope - BBC One London - 29 September 1996 - BBC Genome'.

[9] R. Dawkins, The God delusion. London: Bantam Press, 2006.

[10] Gradual Sayings 111. Pali Text Society, 1973.

[11] J. Holt, Religious Education in the Secondary School: An introduction to teaching, learning and the World Religions (Paperback) - Routledge. 2015.

[12] T. Jinpa, 'Buddhism and science: How far can the dialogue proceed?', Zygon®, vol. 45, no. 4, pp. 871-882, 2010.

[13] 'IOP Physics Subject Knowledge'. [Online]. Available:

http://www.subjectknowledge.org/admin/session/new. [Accessed: 08-Sep-2016].

[14] Dialogues of the Buddha Part 11. London: Pali Text Society, 1977.

[15] Kindred Sayings 1V. London: Pali Text Society, 1980.

[16] S. Boriharnwanaket, A Survey of Paramattha Dhammas. London: zolag, 2006. 
[17] R. Dawkins and J. Coyne, 'One side can be wrong', The Guardian, 01-Sep-2005.

[18] 'Harry Hill's TV Burp', Wikipedia, the free encyclopedia. 16-Aug-2016.

[19] W. Harlen, D. Bell, and Association for Science Education, Principles and big ideas of science education. Hatfield: Association for Science Education, 2010.

[20] '14 Big Ideas of Buddhism by Alan Weller'. [Online]. Available: https://www.haikudeck.com/14big-ideas-of-buddhism-education-presentation-JO34vH3Vnm. [Accessed: 07-Sep-2016].

[21] 'Eratosthenes', Wikipedia, the free encyclopedia. 02-Sep-2016.

[22] N. van Gorkom, The Buddhist Teaching on Physical Phenomena. zolag, 2009.

[23] N. Sawaya, 'The Art of Brick', brickartist. [Online]. Available: http://www.brickartist.com/aboutexhibition.html. [Accessed: 08-Sep-2016].

[24] CPD College, 'Teachers TV: What Would the Buddha have Done?', 24-Mar-2015. [Online]. Available: https://www.youtube.com/watch?v=xW3YImf6AHo. [Accessed: 13-Sep-2016].

[25] 'Scopes Trial', Wikipedia, the free encyclopedia. 17-Jan-2015.

[26] 'The Dhamma Study and Support Foundation'. [Online]. Available: http://www.dhammahome.com/home_en.php. [Accessed: 13-Sep-2016].

[27] A. Weller, 'eBuddhism by Zolag', GitBook, Alan Weller. [Online]. Available: https://www.gitbook.com/@alwell. [Accessed: 14-Sep-2016].

[28] A. Weller, 'Zolag'. [Online]. Available: http://alwell.github.io/Web_Site/. [Accessed: 14-Sep-2016].

[28]2016]. 